\title{
Opportunities for Supporting Latino Immigrants in Emergency and Ambulatory Care Settings
}

\author{
July Lee ${ }^{1}$ [ Janine Bruce ${ }^{1} \cdot$ Nancy Ewen Wang ${ }^{2}$ \\ Published online: 22 July 2020 \\ ○) Springer Science+Business Media, LLC, part of Springer Nature 2020
}

\begin{abstract}
Toughened immigration policies exacerbate barriers to public benefits and health care for immigrants. The objective of this study is to examine the impact of the immigration climate on the utilization of pediatric emergency and ambulatory care services and elucidate ways to best support Latino immigrant families. This is a cross-sectional study involving surveys and interviews with Latino parents ( $\geq 18$ years) in the pediatric emergency department. Forty-five parents completed surveys and 40 were interviewed. We identified two themes on health care utilization: fear of detention and deportation in health care settings, and barriers to pediatric primary care; and two themes on how pediatric providers can best support Latinos: information and guidance on immigration policies, and reassurance and safety during visits. Despite immigration fears, Latino parents continue to seek health care for their children. This highlights the unique access that pediatric providers have to this vulnerable population to address immigration fears and establish trust in the health care system. Health care providers are also perceived as trusted figures from whom Latino families want more information on the latest immigration policies, immigration resources, and education on legal rights during medical visits.
\end{abstract}

Keywords Immigration $\cdot$ Public charge $\cdot$ Latino $\cdot$ Health care utilization $\cdot$ Emergency

\section{Background}

In 2017, Latinos made up $18.3 \%$ of the U.S. population but represented $27.2 \%$ of the population in poverty [1]. Latinos account for nearly one-third of Medicaid enrollees, providing more than half of Latino children with Medicaid coverage [2]. However, toughened immigration policies under the current administration have already resulted in medical consequences amongst Latino immigrants [3-5], as well as an increase in deportation and detention bookings [6]. In February 2018, a draft of the Trump administration's new public charge rule caused increased worry and fear among immigrants [7, 8]. Under the new public charge rule, the use of public benefits such as Medicaid, food stamps, and other programs would disqualify an immigrant's application for

July Lee

julyleec@gmail.com

1 Department of Pediatrics, Stanford University School of Medicine, 1265 Welch Road, X240, Stanford, CA 94305, USA

2 Department of Emergency Medicine, Stanford University School of Medicine, Stanford, CA, USA admission to the U.S. or for lawful permanent resident status $[9,10]$. Even for long-standing immigrants in the U.S., the public charge proposal itself increases fears around detention and deportation and exacerbates barriers to accessing health care $[4,11]$.

With a drop in Latinos' participation in health care programs $[12,13]$, there are concerns that health disparities will widen in an already vulnerable population. The threat of public charge is already causing people to forego benefits for which they and their children are eligible for and nearly 8.3 million children are put at risk of disenrollment from Medicaid, Children's Health Insurance Program (CHIP), or food stamps as a result of public charge [14, 15]. At this point in time, the COVID-19 pandemic has brought to light many of the health inequities that pervade our country, particularly in the Latino population. The new public charge rule went into effect in late February of this year, just around the same time that the coronavirus began to sweep through communities in the U.S. Unfortunately, we have already seen that the pandemic has had the heaviest burden of disease, health care, and health outcomes on the black, Hispanic, Native American, and immigrant communities [16]. Many immigrants at higher risk of COVID-19 have been afraid 
to seek testing or medical care for fear of immigration and deportation, an unfortunate consequence of the anti-immigrant rhetoric propagated in the past few years [17].

Unlike ambulatory care settings such as urgent care or outpatient clinics, the emergency department (ED) is obliged under the Emergency Medical and Treatment Labor Act to see everyone who enters, regardless of citizenship, legal status or ability to pay [18]. This makes the ED a unique study setting to access a population that may otherwise be hard to reach. To our knowledge, this is the first study to examine the impact of the recent immigration climate on the utilization of pediatric emergency and ambulatory care services from the perspective of Latino parents.

\section{Methods}

\section{Study Design/Setting}

The purpose of this study is to understand the impact of the immigration climate on the utilization of pediatric emergency and ambulatory care services by Latino parents. We studied this by surveying and interviewing Latino parents of patients who presented to the pediatric ED at a suburban Northern California hospital between September 2018 and May 2019. The study hospital has an approximate volume of 78,000 patients per year. Children represent $24 \%(18,720)$ of the patient volume, $30-40 \%$ of whom are Latinos. Participants were recruited based on convenience sampling. The study was conducted in patient rooms on varying days of the week and times of day to obtain a diverse study sample. Data were collected using a mixed-methods approach, combining surveys and interview data.

Latino parents ( $\geq 18$ years of age) of children registered in the pediatric ED were eligible. Parents were identified using the child's ethnicity reported in the hospital electronic medical record or parents were asked to confirm they were Latino. We excluded parents of patients with pending hospital admissions, psychiatric chief complaints, or those deemed too sick by the ED physician.

\section{Survey Data Collection and Analysis}

Parents were approached in the pediatric ED to complete an anonymous, self-administered survey in Spanish or English. The survey noted demographics, pediatric emergency and ambulatory care utilization, and parental immigration concerns. Demographic questions were adapted from other published studies and standardized questionnaires [19-22]. Survey questions were tested and revised for clarity and length with 8 pediatric residents before translating and administering the surveys to parents. We tabulated parents' country of birth (used as a proxy for "immigrant" status) and other characteristics in an attempt to determine possible associations.

\section{Interview Data Collection and Analysis}

Following the survey, parents were asked to participate in an anonymous interview examining their perspectives and experiences on the utilization of pediatric emergency and ambulatory care services, and the impact of the political climate on health-seeking behaviors. Interviews were conducted by the study author (J.L.) or by a research assistant. Interviews lasted 10-20 min and were conducted in Spanish or English based on parent preference.

All interviews were audio-recorded and transcribed by Spanish fluent members of the research team (Spanish interviews) or by an online transcription service (English interviews). A codebook was developed inductively from the data through a process of refinement with input from the research team until a final codebook was achieved. Codes were then applied to the transcripts through a process of reviewing and coding excerpts [23, 24]. Co-coders achieved an inter-rater reliability Cohen's kappa score of 0.85 [25]. Major themes and representative quotes were analyzed. The themes were iteratively reviewed, refined, and condensed until final themes were identified [26, 27]. Multiple perspectives were incorporated throughout the review process to check for potential biases and to strengthen the interpretation and credibility of the data [28]. The coding software, Dedoose, was used to organize and facilitate the analysis process.

\section{Results}

The sample size for the interviews was determined based on when the saturation of themes was achieved. Thus data collection ceased at 40 interviews and 45 surveys [29, 30].

\section{Quantitative Survey Findings}

Survey participants $(\mathrm{n}=45)$ completed the surveys in Spanish $(60 \%)$ or English (40\%). Twelve eligible parents declined to participate in the study altogether due to a lack of time or issues related to their child's care. Surveys were administered during the afternoon (71\%) and morning (29\%) hours.

The majority of children were between 0-2 (44\%) and 6-12 years of age (21\%) (Table 1). Half of the parents were employed (24\% full-time, $29 \%$ part-time). Fifty-one percent had a high school diploma or GED. All parents spoke Spanish and $58 \%$ were bilingual. Only $77 \%$ of parents were insured whereas $98 \%$ of children were insured.

The majority of parents were born outside the U.S. (86\%) with $76 \%$ living in the U.S. for 11 years or more (Table 1). 
Table 1 Demographics of participants surveyed in the pediatric emergency department

\begin{tabular}{|c|c|}
\hline Demographics & $\mathrm{n}(\%)$ \\
\hline Child's age & $\mathrm{n}=43$ \\
\hline $0-2$ & $19(44)$ \\
\hline $3-5$ & $8(19)$ \\
\hline $6-12$ & $9(21)$ \\
\hline $13+$ & $7(16)$ \\
\hline Child's gender & $\mathrm{n}=45$ \\
\hline Male & $22(49)$ \\
\hline Female & $23(51)$ \\
\hline Child has insurance & $\mathrm{n}=44$ \\
\hline Yes & $43(98)$ \\
\hline No & $1(2)$ \\
\hline Parent's gender & $\mathrm{n}=45$ \\
\hline Male & $4(9)$ \\
\hline Female & $41(91)$ \\
\hline Parent has insurance & $\mathrm{n}=44$ \\
\hline Yes & $34(77)$ \\
\hline No & $10(23)$ \\
\hline Parent's employment status & $\mathrm{n}=45$ \\
\hline Full-time & $11(24)$ \\
\hline Part-time & $13(29)$ \\
\hline Not employed & $21(47)$ \\
\hline Parent's education & $\mathrm{n}=45$ \\
\hline Some high school or less & $12(27)$ \\
\hline High school diploma or GED & $23(51)$ \\
\hline Some college or more & $10(22)$ \\
\hline Parent's spoken language & $\mathrm{n}=45$ \\
\hline Spanish only & $19(42)$ \\
\hline English and Spanish & $26(58)$ \\
\hline \multicolumn{2}{|l|}{ Immigration } \\
\hline Child's country of birth & $\mathrm{n}=45$ \\
\hline United States & $40(89)$ \\
\hline Outside United States & $5(11)$ \\
\hline Parent's country of birth & $\mathrm{n}=44$ \\
\hline United States & $6(14)$ \\
\hline \multicolumn{2}{|l|}{ Outside United States } \\
\hline Mexico & $30(68)$ \\
\hline Other (Guatemala, El Salvador, Honduras, Peru) & $8(18)$ \\
\hline Years parent has lived in the U.S & $\mathrm{n}=38$ \\
\hline $0-5$ & $3(8)$ \\
\hline $6-10$ & $6(16)$ \\
\hline $11+$ & $29(76)$ \\
\hline Have knowledge of legal rights around immigration & $\mathrm{n}=42$ \\
\hline No & $13(31)$ \\
\hline Yes & $24(57)$ \\
\hline Does not apply & $5(12)$ \\
\hline Ever refrained from applying to public benefits (i.e. Medi-Cal, WIC, CalFresh, free \& reduced lunches, etc.) & $\mathrm{n}=45$ \\
\hline No & $21(47)$ \\
\hline Yes & $18(40)$ \\
\hline Decline to answer & $6(13)$ \\
\hline
\end{tabular}


The majority of children were born in the U.S. (89\%). Due to the small number of parents born in the U.S. (14\%), we did not have sufficient power to come to a quantitative conclusion regarding the association between parents' country of birth (used as a proxy for "immigrant status") and other study characteristics. Only 57\% of parents reported they knew their basic legal rights regarding immigration and $31 \%$ reported they did not (Table 1). Forty percent of parents reported they had ever refrained from applying to public benefits such as Medical, Women, Infants and Children (WIC), Supplemental Nutrition Assistance Program (SNAP), and free and reduced lunches.

\section{Utilization Of Pediatric Emergency And Ambulatory Care Services}

The most common reason for presentation to the pediatric ED was pain-related $(n=23)$, fever $(n=17)$, and respiratory problems $(n=9)$ (Table 2$)$. When parents were asked why they presented to the ED versus going to their child's primary care provider, $50 \%$ felt it was an emergency, $32 \%$ were told to go to the ED by the clinic, and $16 \%$ could not get a timely appointment. Sixty-seven percent had gone to the doctor's office 2 or more times in the last 6 months. There was no association between the number of times the child went to the doctor's office versus the ED.

\section{Qualitative Interview Findings}

Forty parents participated in Spanish $(60 \%)$ or English (40\%) interviews.

\section{Domain 1: Utilization Of Pediatric Emergency And Ambulatory Care Services}

Theme 1: Fear of detention and deportation in health care settings. When asked how the current political climate surrounding immigration has impacted the overall usage of health care services amongst immigrants, parents perceived that immigrants are more hesitant to seek care. Immigrants are afraid to leave their homes or seek help for fear of being discovered and deported by Immigration Customs

Table 2 Utilization of health care services in the pediatric emergency department and primary care setting

\begin{tabular}{|c|c|}
\hline Pediatric emergency department services & $\mathrm{n}(\%)$ \\
\hline Reason for ED visit (multiple reasons selected) & $\mathrm{n}=44$ \\
\hline Pain & $23(52)$ \\
\hline Fever & $17(39)$ \\
\hline Respiratory problem & $9(20)$ \\
\hline Infection & $8(18)$ \\
\hline Trauma/Wound & $1(2)$ \\
\hline Other & $4(9)$ \\
\hline Reason for ED visit versus going to primary care provider & $\mathrm{n}=44$ \\
\hline It was an emergency that could not wait & $22(50)$ \\
\hline I called/went to the clinic and they told me to come to the ED & $14(32)$ \\
\hline I could not get an appointment at the doctor's office & $7(16)$ \\
\hline My child does not have a primary care doctor & $1(2)$ \\
\hline Times the child went to ED in the last 12 months & $\mathrm{n}=44$ \\
\hline $1-2$ & $34(77)$ \\
\hline $2+$ & $10(23)$ \\
\hline \multicolumn{2}{|l|}{ Pediatric primary care services } \\
\hline Child's last well-child check & $\mathrm{n}=45$ \\
\hline Less than a year ago & $36(80)$ \\
\hline More than a year ago & $2(4)$ \\
\hline Has never had a well-child check & $3(7)$ \\
\hline Do not remember & $4(9)$ \\
\hline Times child went to the doctor's office in the last 6 months & $\mathrm{n}=45$ \\
\hline None & $2(4)$ \\
\hline 1 & $13(29)$ \\
\hline 2 & $16(36)$ \\
\hline $3+$ & $14(31)$ \\
\hline
\end{tabular}


Enforcement (ICE) en route to the health care setting or once already there. One parent described, "it is like the person that does not want to be heard because then they will be seen." Several parents also mentioned knowing immigrants who did not seek care in a timely fashion due to these fears of interaction with immigration authorities until their illness progressed too far or it became an emergency (Table 3).

Parents also expressed a fear of detention and family separation in health care settings. Parents mentioned having a fear of being separated from their child if deported and not knowing who would care for that child in the U.S. Furthermore, many parents fear that health care settings will send their personal information to the government, allowing ICE to find their addresses and look for them in their homes. Several parents also mentioned having witnessed an ICE raid in nearby neighborhoods.

Theme 2: Barriers to pediatric primary care. The most common barriers to primary care were long clinic wait times followed by difficulty obtaining a timely appointment. Parents observed that clinic appointments were often delayed due to a high patient load or staff members running behind schedule. Parents also mentioned that appointments were either too far out, difficult to obtain for same-day visits, or that their child's primary care provider was only available on limited days of the week (Table 3). Other parents mentioned difficulties with their child's insurance, including not realizing that the insurance expired or that they had limited insurance coverage. Interview and survey responses also differed. For example, compared to the number of survey respondents who marked no barriers when accessing pediatric primary care services, far fewer of those interviewed said they faced no barriers. This highlights that more nuanced barriers are not revealed in surveys until there is a more trusting and in-depth interaction.

\section{Domain 2: Supporting Latino Immigrant Patients}

Theme 1: Information and guidance on immigration policies. During the interviews, parents offered suggestions to address the unique needs of immigrants. Overwhelmingly, immigrants wanted more information and resources from medical providers, particularly on the latest immigration

Table 3 Themes and representative quotes

Domain 1: Utilization of pediatric emergency and ambulatory care services

Theme 1: Fear of detention and deportation in health care settings

It [immigration climate] is affecting [access to medical care] a lot because sometimes we prefer to endure a medical situation like pain, due to fear that you go to the hospital and get denied medical care, or that suddenly immigration arrives there [health care settings]. So we prefer to wait and endure than to go to a center to seek medical attention. I know of families who have gone through difficult situations in these aspects due to the immigration climate. - Female parent

On one hand, I do have fear [of immigration] because I don't have papers and if my baby gets sick I have heard that immigration has landed in hospitals. So I do fear going to the hospital and bringing my sick baby to the hospital and getting myself arrested at that moment. And what would my young baby do [if I get separated]? That worries me. - Female parent

Theme 2: Barriers to pediatric primary care

The thing is waiting to go in when you go to your appointment. It takes a really long time to go in [to be seen]. It takes like an hour to go into the visit since it's a doctor's visit and that's already having an appointment. - Female parent

With the appointments, that is troublesome. It can take 1 week, 2 weeks [until the appointment] and sometimes one needs an urgent appointment and for that they don't give it [appointment] soon enough. They always say there is not enough [appointment] availability. - Female parent

Domain 2: Supporting Latino immigrant patients

Theme 1: Information and guidance on immigration policies

Yes, there is a way to support [immigrants] such as giving information on where they can look for resources without asking about their immigration status. Like resources from community centers or hospitals that are free. - Female parent

Have a program that could orient our families, bring lawyers who are experts in immigration that can help families that doctors know of. For example, there are lots of instances when our kids are sick and the pediatrician could identify "okay, this family has a lot of worries about her child's health. I could help by bringing together experts in immigration to explain or educate them about their rights." If immigration were to find me right now, I would not know what my rights are. I would not know what to do. I would go into a state of shock, cry, and panic because I do not know what my rights are to be in this country. - Female parent

Theme 2: Reassurance and safety during visits

Let the immigrant patients know that nothing is going to happen [to them] and to not be afraid. Many immigrants don't come here to the hospital because they are afraid that they [hospital] might ask them for documentation and that immigration might come for them. - Female parent

I think just doing as much as they [doctors] can to make them [immigrants] feel comfortable and letting them know that they're safe and that their information isn't going to go out to the wrong people. That they [immigrants] don't have to be scared to come [to health care settings] and ask for help. Just reassuring them [immigrants] that they're okay, they can look for help and that they deserve to get it, and they do have their rights here even though they might feel like they don't. - Female parent 
policies and knowledge of basic legal rights (Table 3). Some parents reported they were no longer renewing public benefits such as WIC, food stamps, or Medi-Cal for themselves after hearing mixed messages regarding the impact of public charge. One parent noted, "right now I don't have insurance, I don't have Medi-Cal. My husband encourages me to apply for Medi-Cal but with what I've heard, I tell him no because I fear asking for Medi-Cal for us because I don't know how it will affect the children." As such, medical providers are in a unique position of trusted authority to provide clarifying information. A few parents also wanted education on legal rights as several parents said they did not know them. One parent noted, "if immigration finds me right now, I wouldn't know what my legal rights are, I don't even know what to do. I would go into a state of shock, crying, and panicked because I don't know my rights ..." (Table 3 ).

Theme 2: Reassurance and safety during visits. When asked how doctors can best support immigrant families, many parents expressed gratitude for their care. Parents stated that immigrants live in fear and encouraged providers to reassure patients that they are safe and that their information will not be shared with immigration authorities (Table 3). Others mentioned that receiving similar treatment by medical providers regardless of appearance or background was also important as they had personally experienced or witnessed discrimination at some point. Some suggested that providers should build rapport with patients, have open conversations, and ensure that patients feel that their care was not inferior based on race or immigration status.

\section{Discussion}

We aimed to understand the impact of the current and proposed immigration policies on Latino parents' utilization of pediatric emergency and ambulatory care services. Eightysix percent of parents were immigrants with the majority of their children born in the U.S. While parents continued to access needed emergency and ambulatory care services for their children, they revealed concerns about deportation and family separation as well as ideas about how providers can best support immigrants during these charged political times. This study is particularly relevant during a time when current policies have already resulted in a decrease in Medicaid enrollment [12, 13].

Our study shows that despite a fear of deportation, Latino families are committed to their children's health and are still seeking pediatric emergency and ambulatory care services. This finding suggests that pediatric providers still have unique direct access to a vulnerable population-immigrant parents-who may otherwise avoid the utilization of health care services for themselves $[4,31]$. Since the most recent public charge ruling was proposed, many parents have disenrolled themselves from medical insurance but the overwhelming majority continue to keep their children enrolled. Still, parents express fear of immigration presence in health care settings which can cause delays in seeking care for themselves and their families. Delays in seeking care lead to undertreatment of illness which increases school absenteeism and parental work absence. In the case of pediatric asthma, undertreatment led to a loss of parental productivity of \$719 million in 1996 alone [32].

Our findings also suggest that more needs to be done to mitigate the fears of this vulnerable immigrant population when they seek health care. Many parents in our study had a general fear of deportation or that personal information would be shared with immigration authorities in health care settings. This suggests that providers need to do more to visibly support the rights of Latino families who have any reason to fear immigration authorities. For example, ICE has a policy that treats medical care facilities as "sensitive locations," where enforcement operations should be limited [33]. However, the "sensitive locations" policy is not applied evenly in the U.S [34]. Since health care facilities are now more likely to have encounters with ICE, staff should take steps to establish location-specific policies that protect their undocumented populations [35]. Health care settings should train all staff about patient legal rights and have visibly clear policies and procedures regarding encounters with immigration authorities including training a designated staff to speak to immigration agents and request warrants from agents to assess its validity $[34,36]$. An alert system should also be established to inform staff of immigration presence [37]. Having visible policies in place could provide the reassurance and safety that many parents expressed they wanted when seeking medical care. Such policies will also give medical providers the confidence to reassure patients and their families that they are safe and that their personal information will not be shared with immigration authorities.

Lastly, our study showed that Latinos want more education around immigration, the public charge rule, legal rights, and referral to resources during health care visits. Caregivers trust in pediatricians' ability to provide adequate health services and similarly trust them in other capacities [38]. As such, health care settings are unique havens where parents can safely obtain information about legal rights, learn about immigration policies, and receive referrals to immigration resources and legal aid in the community. In our study, many families who qualify for public benefits are not applying or renewing their public benefits due to fear of the implications that the new public charge rule could have on themselves and their families. Unfortunately, this means that many families are not accessing the services they qualify for that address many social determinants of health [39]. Our study also highlights that many of our parents did not know their basic legal rights around immigration. Thus, health care providers 
should identify and collaborate with medical-legal partnerships in their communities as they have been shown to benefit families and improve health outcomes [40]. Resources to these medical-legal partnerships and information about legal rights could also be incorporated into the After Visit Summary paperwork that is handed to every patient before discharge from the clinic or ED. At a time when Latino patients feel stress around their immigration status, physicians can play an important role and offer resources to provide emotional support to their patients and immigrant parents [41].

\section{Limitations}

This study has several limitations. First, this study was done at a single academic pediatric ED in California and may not be generalizable to other locations. However, California is a diverse state with the largest number of Latinos in the nation [42]. Second, we tried to capture as many eligible participants as possible in the ED, but many parents were not screened for eligibility due to research staff availability. Despite this inherent limitation, a saturation of themes was reached. Third, due to the sensitive nature of immigration questions and concerns of being identified, we did not directly ask about the parent's legal status. However, we have a high degree of confidence in our findings given the confidential nature of our study and several parents' voluntary disclosure of their undocumented status and their immigration fears. Lastly, this study was conducted in the ED setting only. We think there may be additional value in extending and conducting this study in a primary care setting. This presents as an opportunity for future research.

\section{Conclusion and New Contribution to Literature}

This is the first study to explore the impact of our immigration climate on the utilization of pediatric emergency and ambulatory care services from the perspective of Latino parents. We have shown that parents have a fear of immigration and deportation in health care settings, yet continue to bring their children to seek needed health care services in the ED and outpatient clinics. This highlights the unique access that pediatric providers have to a vulnerable population to address fears, misconceptions about immigration issues, and reestablish trust in the health care system. Health care providers are also perceived as trusted authority figures from whom immigrant families want more information on the latest immigration policies such as public charge, immigration resources including legal aid, and education on legal rights during medical visits.
Acknowledgements This study was supported by the Stanford Pediatrics Resident Research Grant. We thank the peers and faculty from the Community Engagement and Advocacy Scholarly Concentration in the Department of Pediatrics at Stanford for their mentorship and support; to Monica De La Cruz for her guidance on data analysis and to Jesus Pineda-Ramirez for his assistance with data collection. We extend special thanks to the staff from the Stanford Hospital Emergency Department and to the families who participated in this study.

Funding All phases of this study were supported by the Stanford Pediatrics Resident Research Grant. The authors have indicated they have no financial relationships relevant to this article to disclose.

\section{Compliance with Ethical Standards}

Conflict of Interests The authors declared that they have no competing interests.

Ethical Approval This study was conducted in accordance with the ethical standards of the institutional review board. The study was granted a waiver of documentation of consent by the Stanford Institutional Review Board.

Informed Consent Parents received a study information sheet in Spanish or English and verbal consent was obtained before participating. Our Institutional Review Board granted a waiver of documentation of consent. Survey and interview participants received a \$5 and \$15 gift card respectively. Verbal informed consent to participate in the study was obtained from every participant.

\section{References}

1. US Census Bureau. (n.d.). Hispanic poverty rate hit an all-time low in 2017. Retrieved May 18, 2020, from https://www.censu s.gov/library/stories/2019/02/hispanic-poverty-rate-hit-an-alltime-low-in-2017.html

2. NCPSSM. (n.d.). Hispanics and medicare-NCPSSM. NCPSSM. Retrieved May 18, 2020, from https://www.ncpssm.org/our-issue s/medicare/hispanics-and-medicare/

3. Kennedy, K. (2018). Deportation fears have legal immigrants avoiding health care. AP NEWS; Associated Press. https://apnew s.com/9f893855e49143baad9c96816ec8f731

4. Callaghan, T., Washburn, D. J., Nimmons, K., Duchicela, D., Gurram, A., \& Burdine, J. (2019). Immigrant health access in Texas: policy, rhetoric, and fear in the Trump era. BMC Health Services Research, 19(1), 342. https://doi.org/10.1186/s12913-019-4167-1.

5. Artiga, S., \& Ubri, P. (2017). Living in an immigrant family in America: how fear and toxic stress are affecting daily life, wellbeing, \& health. Menlo Park, CA: Kaiser Family Foundation.

6. ERO FY18 Achievements (2019). U.S. Immigration and Customs Enforcement. https://www.ice.gov/features/ERO-2018

7. Feshir, R. (2018). "Public charge" rule blamed for "chilling effect" among immigrants. MPR News. https://www.mprnews.org/ story/2018/10/23/public-charge-rule-blamed-for-chilling-effec t-among-immigrants

8. Read the Trump administration's draft proposal penalizing immigrants who accept almost any public benefit. (n.d.). Washington Post. Retrieved September 1, 2019, from https://apps.washington post.com/g/documents/world/read-the-trump-administrations -draft-proposal-penalizing-immigrants-who-accept-almost-anypublic-benefit/2841/ 
9. Public charge - national immigration law center. (n.d.). National Immigration Law Center. Retrieved August 25, 2019, from https:// www.nilc.org/issues/economic-support/pubcharge/

10. Inadmissibility on public charge grounds. (2018). Federal Register. https://www.federalregister.gov/documents/2018/10/10/2018-21106 /inadmissibility-on-public-charge-grounds

11. Penichet-Paul, C. (2019). Legislative Bulletin. National Immigration Forum. https://immigrationforum.org/article/legislative-bulle tin-thursday-august-15-2019/

12. Jenco, M. (2019). Report: 4.3 million children uninsured in 2018. AAP News. https://www.aappublications.org/news/2019/09/10/pover ty091019

13. Simmons-Duffin, S. (2019). Fewer children had health insurance in 2018 than year before, census data shows. NPR.org. https://www. npr.org/sections/health-shots/2019/09/10/759522995/fewer-child ren-had-health-insurance-in-2018-census-data-shows

14. Lancet, T. (2019). US public charge rule: pushing the door closed. The Lancet, 393(10187), 2176. https://doi.org/10.1016/S0140 $-6736(19) 31233-4$.

15. Zallman, L., Finnegan, K. E., Himmelstein, D. U., Touw, S., \& Woolhandler, S. (2019). Implications of changing public charge immigration rules for children who need medical care. JAMA Pediatrics. https://doi.org/10.1001/jamapediatrics.2019.1744.

16. van Dorn, A., Cooney, R. E., \& Sabin, M. L. (2020). COVID-19 exacerbating inequalities in the US. The Lancet, 395(10232), 12431244. https://doi.org/10.1016/S0140-6736(20)30893-X.

17. McFarling, U. L., Branswell, H., Sataline, S., Boodman, E., Zia, S., \& Joseph, A. (2020). "We"ll be deported': immigrants fear seeking Covid-19 tests or care-STAT. STAT. https://www.statnews. com/2020/04/15/fearing-deportation-many-immigrants-at-highe r-risk-of-covid-19-are-afraid-to-seek-testing-or-care/

18. Kline, M. (2011). National immigration policy and access to health care. American College of Physicians Observer. https://www.acpon line.org/acp_policy/policies/natl_immigration_policy_access_healt hcare_2011.pdf

19. Billioux, A., Verlander, K., Anthony, S., \& Alley, D. (2017). Standardized screening for health-related social needs in clinical settings: the accountable health communities screening tool. National Academy of Medicine. https://doi.org/10.31478/201705b.

20. U.S. Census Bureau. (2017). Encuesta Nacional de Salud de los Niños. https://www.census.gov/content/dam/Census/programs-surve ys/nsch/tech-documentation/questionnaires/2017/2017\%2520N SCH\%2520SPANISH\%2520TOPICAL1\%2520INFO.pdf

21. Guidance for conducting the consumer assessment of healthcare providers and systems (CAHPS®) 5.0H Child Survey. (2012, December). https://www.medicaid.gov/medicaid/quality-of-care/ downloads/cahpsbrief.pdf

22. Estrada, A. L., Treviño, F. M., \& Ray, L. A. (1990). Health care utilization barriers among Mexican Americans: evidence from HHANES 1982-84. American Journal of Public Health, 80(Suppl), 27-31. https://doi.org/10.2105/ajph.80.suppl.27.

23. Fereday, J., \& Muir-Cochrane, E. (2006). Demonstrating rigor using thematic analysis: a hybrid approach of inductive and deductive coding and theme development. International Journal of Qualitative Methods., 5(1), 80-92. https://doi.org/10.1177/160940690600500 107.

24. Fonteyn, M. E., Vettese, M., Lancaster, D. R., \& Bauer-Wu, S. (2008). Developing a codebook to guide content analysis of expressive writing transcripts. Applied Nursing Research: ANR, 21(3), 165-168. https://doi.org/10.1016/j.apnr.2006.08.005.

25. Guest, G., MacQueen, K. M. \& Namey, E. E. (2012). Validity and reliability (credibility and dependability) in qualitative research and data analysis. In Guest, G., MacQueen, K. M., \& Namey, E. E. Applied thematic analysis (pp. 79-106). SAGE Publications. https ://doi.org/10.4135/9781483384436.

26. Vaismoradi, M., Jones, J., Turunen, H., \& Snelgrove, S. (2016). Theme development in qualitative content analysis and thematic analysis. Journal of Nursing Education and Practice. https://doi. org/10.5430/jnep.v6n5p100.

27. Guest, G., MacQueen, K., \& Namey, E. (Eds.). (2012a). Themes and codes. In Applied thematic analysis (pp. 49-78). SAGE publications. https://doi.org/10.4135/9781483384436.n3

28. Saldaña, J. (2009). The coding manual for qualitative researchers. Sage Publications Ltd.

29. Hennink, M. M., Kaiser, B. N., \& Marconi, V. C. (2017). Code saturation versus meaning saturation: how many interviews are enough? Qualitative Health Research, 27(4), 591-608. https://doi. org/10.1177/1049732316665344.

30. Saunders, B., Sim, J., Kingstone, T., et al. (2018). Saturation in qualitative research: exploring its conceptualization and operationalization. Quality \& Quantity, 52(4), 1893-1907. https://doi.org/10.1007/ s11135-017-0574-8.

31. Fleming, P. J., Lopez, W. D., Mesa, H., et al. (2019). A qualitative study on the impact of the 2016 US election on the health of immigrant families in Southeast Michigan. BMC Public Health, 19(1), 947. https://doi.org/10.1186/s12889-019-7290-3.

32. Wang, L. Y., Zhong, Y., \& Wheeler, L. (2005). Direct and indirect costs of asthma in school-age children. Preventing Chronic Disease., 2(1), A11.

33. Morton, J. (2011). Enforcement actions at or focused on sensitive locations. https://www.ice.gov/doclib/ero-outreach/pdf/10029 2-policy.pdf

34. Saadi, A., Ahmed, S., \& Katz, M. H. (2017). Making a case for sanctuary hospitals. JAMA., 318(21), 2079-2080. https://doi. org/10.1001/jama.2017.15714.

35. Saadi, A., \& McKee, M. (2018). Hospitals as places of sanctuary. In $B M J$ (p. 361:k2178). https://doi.org/10.1136/bmj.k2178

36. Health Care Providers and Immigration Enforcement: Know Your and Your Patients' Rights-National Immigration Law Center. (2017). National Immigration Law Center. https://www.nilc.org/ issues/immigration-enforcement/healthcare-provider-and-patientsrights-imm-enf/

37. Stoughton, S., \& Hampton, K. (n.d.). Not in my exam room-how U.S. immigration enforcement is obstructing medical care. Physician for Human Rights. Retrieved September 28, 2019, from https://phr. org/our-work/resources/not-in-my-exam-room/

38. Steinberg, J. R., Bruce, J. S., Marin-Nevarez, P., Phan, K., Merrell, S. B., \& Chamberlain, L. J. (2018). Early childhood learning and the pediatrician: a qualitative study among diverse, low-income caregivers. Journal of Developmental and Behavioral Pediatrics: JDBP, 39(5), 376-386. https://doi.org/10.1097/DBP.0000000000000564.

39. Parmet, W. (2019). The trump administration's new public charge rule: implications for health care \& public health. HealthAffairs. https://www.healthaffairs.org/do/10.1377/hblog20190813.84831/ full/

40. Murphy, J. S., Lawton, E. M., \& Sandel, M. (2015). Legal care as part of health care: the benefits of medical-legal partnership. Pediatric Clinics of North America, 62(5), 1263-1271. https://doi. org/10.1016/j.pcl.2015.06.001.

41. Kuczewski, M. G., Mejias-Beck, J., \& Blair, A. (2019). Good sanctuary doctoring for undocumented patients. AMA Journal of Ethics, 21(1), E78-E85. https://doi.org/10.1001/amajethics.2019.78.

42. Stepler, R., \& Hugo Lopez, M. (2016). Ranking the Latino population in the states. Pew Research Center's Hispanic Trends Project. https://www.pewresearch.org/hispanic/2016/09/08/4-ranking-thelatino-population-in-the-states/

Publisher's Note Springer Nature remains neutral with regard to jurisdictional claims in published maps and institutional affiliations. 